\title{
Quantification of Tamoxifen in Pharmaceutical Formulations Using Micellar Liquid Chromatography
}

\author{
Juan Peris-Vicente, ${ }^{\dagger}$ Samuel Carda-Broch, and Josep Esteve-Romero \\ Dep. de Química Física i Analítica, E.S.T.C.E., Universitat Jaume I, 12071 Castelló, Spain
}

\begin{abstract}
This paper describes a micellar liquid chromatographic method used to analyze tamoxifen (TAMO) in pharmaceutical formulations, while focusing in its interesting features. Solid samples were solved in a micellar solution, irradiated at $254 \mathrm{~nm}$, filtered and injected. Extraction steps were avoided and thus expediting the procedure. Tamoxifen was resolved in $<5 \mathrm{~min}$, using a mobile phase containing $0.15 \mathrm{M}$ sodium dodecyl sulfate- $7 \%$ pentanol at $\mathrm{pH} 3$, running at $1.5 \mathrm{~mL} / \mathrm{min}$ under an isocratic mode at $40^{\circ} \mathrm{C}$ through a $\mathrm{C} 18$ column. Detection was achieved by fluorescence by excitation at $260 \mathrm{~nm}$ and emission at $380 \mathrm{~nm}$. The validation was performed following the requirements of the International Conference on Harmonization (ICH) Tripartite Guidelines in terms of: specificity, sensitivity, calibration range $(0.2-20 \mathrm{mg} / \mathrm{L})$, accuracy $(98.8-101.7 \%)$, precision $(<1.5 \%)$ and robustness $(<6.2 \%)$. The method was applied to quantify TAMO in TAMO citrate tablets supplied in Spain, and was found appropriate for the quality control of TAMO formulations.
\end{abstract}

Keywords Cancer, formulation, micellar, tamoxifen, validation

(Received May 15, 2014; Accepted July 24, 2014; Published September 10, 2014)

\section{Introduction}

Breast cancer is the most diagnosed cancer in women, especially post-menopausic, with a mortality rate of nearly $20 \%$, and a growing incidence. ${ }^{1}$ Approximately $70 \%$ of the detected tumors express the estrogen receptor (ER). Tamoxifen (TAMO), a non-steroidal triphenylethylene antiestrogen drug, was approved in 1977 by Food and Drug Administration for adjuvant treatment against metastasis breast cancer, with impressive results. ${ }^{2}$ Tamoxifen competitively inhibits oestradiol binding to the estrogen receptor, starving the cancer cells, and preventing tumor growth. ${ }^{3}$ Currently, it is the endocrine therapy of choice for all stages of ER-positive breast cancer, ${ }^{4}$ and is also prescribed as a chemopreventive therapeutic agent to women with high risk of developing this disease. ${ }^{5}$ However, TAMO treatment has also several problems, as adverse side effects, doubtful long-term safety, ${ }^{6}$ strong variability in response, ${ }^{7}$ and development of tumour resistance, leading to relapse. ${ }^{8}$ Moreover, a decrease of survival rate has been associated to a lack of compliance with adjuvant TAMO therapy. ${ }^{9}$

Tamoxifen is a weak base, with a value of minus logarithm of the basic dissociation constant $\left(\mathrm{p} K_{\mathrm{b}}\right)$ of 5.1 and highly hydrophobic, according to the value of the logarithm of the partition coefficient octanol/water $(\log P \mathrm{O} / \mathrm{w}), 6.64$, with low solubility in water. $^{10}$ It is converted to its citrate salt for commercial purposes, to increase the aqueous solubility and therapeutic efficacy. ${ }^{11}$ Thus, TAMO is supplied in pharmaceuticals as oral tablets of TAMO citrate, with a molecular weight $\left(M_{\mathrm{W}}\right)$ of $563.4 \mathrm{~g} / \mathrm{mol}$. It is a white, odourless and fine crystalline powder, moderately soluble in water

† To whom correspondence should be addressed.

E-mail: vicentej@uji.es
$(0.5 \mathrm{mg} / \mathrm{mL})$ and in acid $(0.2 \mathrm{mg} / \mathrm{mL}){ }^{12} \quad$ Pharmaceutical producers have to check that the TAMO formulations contain the amount of active principle indicated in the label. Besides, TAMO therapy is long-term; therefore some patients are enticed to initially purchase a large amount of tablets and, improving the risk to take the last ones after the expiration date, and then containing a non-reliable amount of TAMO ${ }^{13}$ Due to the high price of formulations and the long duration of the treatment, the overall cancer therapy is extremely expensive. This has encouraged the production of generic formulations, especially in developing countries, by non-certified trade marks. The quality of these generics must be rigorously controlled and assured prior to their distribution by medical stores. ${ }^{14}$ In some cases, counterfeit formulations with doubtful quality are produced in illegal laboratories, and are offered at minor cost on the black market as legitimate tablets. ${ }^{15,16}$ Since the dose can affect the final outcome of the treatment and side effects, the amount of active principle in tablets must be accurately known. ${ }^{3}$ For these reasons, clinicians and pharmacist must dispose of reliable methods to quantify tamoxifen in commercial pharmaceutical formulations.

A limited amount of analytical methods have been developed to analyze TAMO in formulations. UV-Visible spectrophotometry has been proposed as a rapid method to quantify TAMO, prior absorbance enhancing by complexation ${ }^{17,18}$ or derivatization with $p$-chloranilic acid, ${ }^{19}$ which requires a liquid/liquid extraction. Other methods are based on separative techniques, such as electrophoresis, ${ }^{20}$ gas chromatography ${ }^{15,21}$ and liquid chromatography, ${ }^{15,16}$ in order to reduce interferences from the excipients. Due to the low solubility of TAMO in water, these methods require the use of organic solvents. Liquid chromatography is preferred, because of its accessibility in hospital laboratories. In this case, the detection is performed by UV-Visible absorbance ${ }^{15}$ and mass spectrometry (MS). ${ }^{16}$ This 
last one shows higher analytical performance, but it is an expensive instrumentation, which requires especial care. ${ }^{22}$ HPLC coupled with fluorescence detection (FLD) has been widely used to detect TAMO in biological samples, because of the high sensitivity, specificity and relatively low cost, compared to other detectors. ${ }^{23-27}$ However, it has not been previously used to our knowledge to analyze TAMO citrate pharmaceutical formulations. As TAMO is not fluorogen, it must be previously activated by photo-cyclization induced by irradiation to form a derivative with a phenanthrene core, which shows intense fluorescence. ${ }^{28-30}$

We have previously developed a micellar liquid chromatographic (MLC) method, coupled with FLD for the quantification of tamoxifen in plasma with excellent results. ${ }^{29,30}$ Anionic sodium dodecyl sulfate (SDS) was used as a surfactant, due to its low cost, critic micellar concentration, Krafft point and viscosity, as well as high solubility in water and biodegradability. ${ }^{31}$ This method can be adapted to analyze solids. ${ }^{32}$ Micellar solutions are extremely useful when dealing with hydrophobic compounds. These are solubilized by interactions with the micelle, avoiding the use of organic solvents in sample preparation. ${ }^{33}$ The benefits of MLC are also extended to chromatographic separation. Micellar mobile phases use non-polluting inorganic reagents, and reduced amount of alcohol (up to 12.5\%). ${ }^{34}$ Besides, SDS interacts with the alcohol, preventing its evaporation. As results, they are less toxic, less flammable, more stable and environmental-friendly and relatively inexpensive if compared to hydroorganic mobile phases. ${ }^{35}$ MLC has been useful in the determination of a large amount of drugs, as ergot alkaloids, ${ }^{36}$ antibiotics, ${ }^{37}$ disulfiram, ${ }^{38}$ antidepressants, ${ }^{39}$ antianginals, ${ }^{40}$ diuretics, ${ }^{41}$ benzodiazepines, phenethylamines, antihistamines, vitamins and corticosteroids ${ }^{42}$ in pharmaceutical formulations.

The aim of the work is to develop a simple, inexpensive, sensitive and environmentally friendly analytical method to measure the quantity of TAMO in pharmaceutical formulations. The selected technique was micellar liquid chromatography (using SDS as surfactant) coupled to fluorescence detection. The use of organic solvents would be avoided in sample preparation. Tamoxifen should be eluted without interferences in a short analysis time. Quantification results must be reliable and with low variability. The method ought to be validated following the requirements of the Tripartite Harmonized ICH Guidelines in terms of the linear interval, linearity, limits of detection (LOD) and quantification (LOQ), precision, accuracy and robustness. ${ }^{43}$ Finally, the developed analytical method would be applied to verify the quantity of TAMO in commercial TAMO citrate tablets distributed in Spain.

\section{Experimental}

\section{Apparatus and instrumentation}

Solids were weighted with a Mettler-Toledo analytical balance (Greifensee, Switerland). A Ultrasons-H bath (Selecta, Abrera, Spain) was used to ultrasonicate the solutions. The $\mathrm{pH}$ measures were performed using a GLP 22 potentiometer (Crison, Barcelona) equipped with a combined $\mathrm{Ag} / \mathrm{AgCl} / \mathrm{glass}$ electrode. The samples were irradiated with a Philips original home solaria UV lamp (Philips, Eindhoven, The Netherlands).

The chromatograph was a Series HP-1100 system (Agilent Technologies, Palo Alto, CA). It was equipped with an isocratic pump, a degasser, and autosampler and a fluorescence detector. The column was a Kromasil C18 $(150 \times 4.6 \mathrm{~mm}$; particle size $5 \mu \mathrm{m}$ : pore size $100 \AA$, working $\mathrm{pH}$ range $1.5-7.5$ ) from
Sclarlab (Barcelona, Spain). The signal was acquired by a personal computer connected to the chromatograph by means of an Agilent Chemstation Version B.01.01. The special care needed when using micellar solutions as mobile phases has been detailed. ${ }^{44}$ Under these conditions, the column had a life span of nearly 1000 injections.

\section{Chemicals}

Tamoxifen standard (purity $>99.5 \%$ ) was purchased from Sigma (St. Louis, MO). Sodium dodecyl sulfate (purity $>99.0 \%$ ) was supplied by Merck (Darmstadt, Germany). Hydrochloride acid, sodium hydroxide and sodium dihidrogenphosphate (reagent grade), methanol and pentanol (HPLC grade) were acquired from Scharlab (Barcelona, Spain). An ultrapure generator device (Millipore S.A.S., Molsheim, France) was used to purify deionized water to ultrapure water. This ultrapure water was used to prepare all solutions and mobile phases.

\section{Solutions and mobile phases}

Standard solutions: a $200-\mathrm{mg} / \mathrm{L}$ stock solution of TAMO was prepared by solving an adequate amount of standard in few milliliters of methanol, and then diluting with water. Working solutions were prepared by successive dilutions of the stock solution with $0.05 \mathrm{M}$ at $\mathrm{pH}$ 3. All solutions were stored at $4{ }^{\circ} \mathrm{C}$ in the dark, and monthly renewed.

Pharmaceutical solutions: Commercially available tablets of TAMO were finely powdered using agate mortars. The appropriate amount of pharmaceutical to prepare a $10-\mathrm{mg} / \mathrm{L}$ TAMO solution was weighted and introduced in a flask. The solid was solved in few milliliters of methanol, and then the flask was filled up to the mark with a 0.05-M SDS-pH 3 solution. Further dilutions were performed with $0.05 \mathrm{M}$ SDS at pH 3.

Tamoxifen solutions (standard or pharmaceuticals) were kept in amber flasks so as to avoid the photodegradation of the drug.

Micellar solutions: they were prepared by weighting an appropriate amount of SDS and sodium dihydrogenophosphate buffer $(0.01 \mathrm{M})$ and solving them in water. The $\mathrm{pH}$ was adjusted by adding drops of $\mathrm{HCl}$ or $\mathrm{NaOH}$ to the desired value. Furthermore, the adequate volume of pentanol was added and the volumetric flask was filled up to the mark with water.

All solutions and mobile phases were ultrasonicated to ensure total solubilization, and filtered through $0.45 \mu \mathrm{m}$ nylon membranes (Micron Separations, Westboro, MA).

\section{Sample treatment and chromatographic conditions}

A volume of $0.1 \mathrm{~mL}$ of already filtered solution containing TAMO (standard or pharmaceutical sample), was introduced into a see-through $6 \mathrm{~mm}$-diameter small pulled-point glass vial. The mixture was irradiated at $254 \mathrm{~nm}$ for $20 \mathrm{~min}$ at $40 \mathrm{~W}$. The vial was pasted on the irradiation source. A volume of $0.020 \mathrm{~mL}$ of the aliquot was injected into the chromatographic system.

The elution of TAMO was performed using a mobile phase containing $0.15 \mathrm{M}$ SDS-7\% pentanol at $\mathrm{pH} 3$, running through the $\mathrm{C} 18$ column at $1.5 \mathrm{~mL} / \mathrm{min}$ at $40^{\circ} \mathrm{C}$. The detection was performed by fluorescence; the excitation and emission wavelengths were set at 260 and $380 \mathrm{~nm}$, respectively.

\section{Results and Discussion}

\section{Optimization of the sample treatment}

The experimental procedure was taken from a previously published paper devoted to the analysis of TAMO in a plasma sample, ${ }^{29,30}$ and adapted to a different matrix: the tablet. The 
irradiation conditions were kept. The filtering was performed before the irradiation step, taking a large volume, because the filtering of a small amount of sample increases the percentage loss of the sample. Pharmaceutical solutions are cleaner than plasma samples, since they contain fewer amounts of suspended particles. Therefore, it is less harmful for the column and the chromatographic system. Therefore, the aliquot was not diluted before injection, in order to improve the sensitivity.

The composition of the micellar solution used to solve the tablet extraction micellar solution was optimized by considering the extraction efficiency. Three micellar solutions were prepared at several concentrations of SDS $(0.05 ; 0.010$ and $0.15 \mathrm{M})$ and $\mathrm{pH}$ (3 and 7). Furthermore, the same amount of powdered tablet was solved in them. These prepared pharmaceutical solutions were analyzed, and the peak area was found similar in all cases. The selected SDS amount was $0.05 \mathrm{M}$ in order to reduce the mass of reagent wasted. The $\mathrm{pH}$ was 3 , in order to avoid the change of $\mathrm{pH}$ when the aliquot reaches the mobile phase.

\section{Optimization of the chromatographic conditions}

A pharmaceutical solution was analyzed under the chromatographic conditions indicated. ${ }^{30}$ The results were found to be similar, but the front of the chromatogram was baselinelike, instead of the intense protein band at $\approx 4$ min observed in plasma analysis. No other peaks were detected. Therefore, the main chromatographic conditions (stationary phase, surfactant, $\mathrm{pH}$, wavelength detection) were kept, but the mobile phase was modified so as to reduce analysis time. In this case, there is no risk of interference with the front of the chromatogram, regardless of the quick elution of tamoxifen.

The use of a more hydrophobic alcohol would increase the elution strength of the mobile phase; therefore, pentanol was used instead of butanol. Using a mobile phase composed of $0.15 \mathrm{M}$ SDS $7 \%$ pentanol at $\mathrm{pH} 3$, TAMO is eluted at $\approx 3.5 \mathrm{~min}$ with an efficiency of 4587 theoretical plates and an asymmetry of 1.15. Figure 1 shows a chromatogram obtained by the analysis of a solution of $5 \mathrm{mg} / \mathrm{L}$ TAMO solved in $0.05 \mathrm{M}$ SDS at $\mathrm{pH} 3$.

\section{Method validation}

The method was validated following the requirements of the ICH Tripartite Harmonized Guideline, especially devoted to the analysis of drugs. ${ }^{43}$ The entire validation was performed using standard solutions of TAMO solved in $0.05 \mathrm{M}$ SDS at $\mathrm{pH} 3$. The studied parameters were: linearity, linear range, sensitivity, as LOD and LOQ, inter- and intra-day accuracy, repeatability, intermediate precision and robustness.

a) Linearity: For linearity studies, seven TAMO solutions at increasing concentrations, from 0.2 to $20 \mathrm{mg} / \mathrm{L}$, were analyzed by triplicate. The calibration curve was constructed by correlating the peak area vs. TAMO concentration by leastsquare linear regression. The final slope, $y$-intercept and determination coefficient were:

$$
A=(1338 \pm 7)[\mathrm{TAMO}]+(10 \pm 60), \quad r^{2}=0.9998,
$$

where $A$ is the luminescence in arbitrary units and the concentration is in $\mathrm{mg} / \mathrm{L}$.

LOD and LOQ were calculated as 3.3 and 10-times the standard deviation of the blank divided by the sensitivity. The standard deviation of the blank was the standard deviation of the signal obtained by ten measurements of a blank solution of $0.05 \mathrm{M}$ at $\mathrm{pH}$ 3. The sensitivity was the slope of the calibration curve. LOD and LOQ were 70 and $200 \mathrm{ng} / \mathrm{mL}$, respectively.

b) Accuracy and precision: These parameters were evaluated by

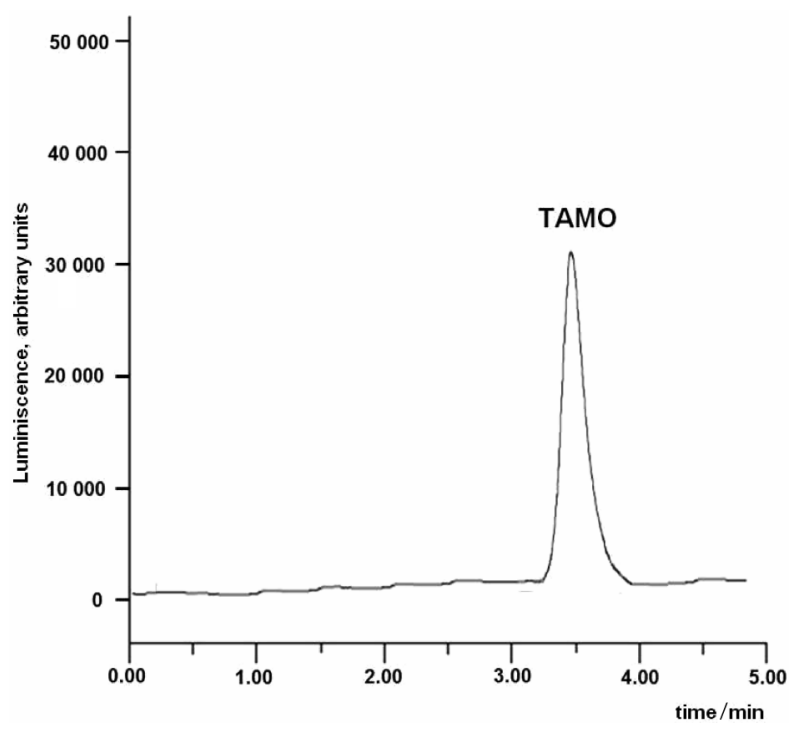

Fig. 1 Chromatogram obtained by the analysis of a solution of $5 \mathrm{mg} / \mathrm{L}$ TAMO solved in $0.05 \mathrm{M}$ SDS at $\mathrm{pH} 3$ under the optimized conditions.

Table 1 Results obtained by precision and accuracy studies

\begin{tabular}{rrccc}
\hline $\begin{array}{c}\text { Concentration/ } \\
\mathrm{mg} \mathrm{L}^{-1}\end{array}$ & $\begin{array}{c}\text { Intraday } \\
\text { Accuracya } \\
\%\end{array}$ & $\begin{array}{c}\text { Interday } \\
\text { Accuracy } \\
\%\end{array}$ & $\begin{array}{c}\text { Repeatability } \\
\%\end{array}$ & $\begin{array}{c}\text { Intermediate } \\
\text { precision }^{\mathrm{b}}, \%\end{array}$ \\
\hline 1 & 101.7 & 101 & 1.5 & 1.3 \\
5 & 98.8 & 99.2 & 0.9 & 1.1 \\
10 & 100.7 & 99.8 & $0.5^{\mathrm{c}}$ & 0.3 \\
\hline
\end{tabular}

a. $n=5$.

b. $n=6$.

analyzing $(n=6)$ standard solutions with $1 ; 5$ and $10 \mathrm{mg} / \mathrm{L}$. The intraday accuracy was calculated as the quotient of the average value of the measured concentrations and the true value. The repeatability was measured as the relative standard deviation of the signal provided by the detector. These values were calculated while performing all of the analysis during a short time on the same day. The interday accuracy and intermediate precision were calculated as the average values of intraday analysis performed on five different days over a 3-months period. The results are given in Table 1 .

In all of the studied range, the method shows low variability $(<1.5 \%)$ and the measured concentrations were close to the correct values $(98.8-101.7 \%)$, indicating the high quality of the quantitative results.

c) Robustness: The variation of the main chromatographic results (peak area and retention time) was evaluated in front of small changes of the main mobile phase conditions (SDS and pentanol concentration, $\mathrm{pH}$ and flow rate). The oscillation of each experimental condition was separately studied.

A standard solution of $10 \mathrm{mg} / \mathrm{L}$ was used to examine the robustness. For each parameter, the relative standard deviation of the peak area and the retention times obtained at the optimized value, slightly over and slightly below were calculated $(n=3$ in each case). The other parameters remain at their optimized values. The evaluated levels and the corresponding results can be seen in Table 2 . The low variability in the peak area $(<3.5 \%)$ and the retention time $(<6.2 \%)$ indicates that these data are not 
Table 2 Evaluation of the robustness of the MLC method $(n=3)$

\begin{tabular}{lccc}
\hline $\begin{array}{c}\text { Mobile } \\
\text { phase parameter }\end{array}$ & Level & $\begin{array}{c}\text { Retention time } \\
\text { (RSD, \%) }\end{array}$ & $\begin{array}{c}\text { Peak area } \\
\text { (RSD, \%) }\end{array}$ \\
\hline Concentration SDS/M & $0.145-0.155$ & 3.9 & 2.4 \\
Pentanol, \% & $6.9-7.1$ & 4.5 & 3.5 \\
pH & $2.9-3.1$ & 2.1 & 1.2 \\
Flow/mL min ${ }^{-1}$ & $1.45-1.55$ & 6.2 & 1.4 \\
\hline
\end{tabular}

Table 3 Label claims obtained for commercial TAMO citrate tablets

\begin{tabular}{|c|c|c|}
\hline Pharmaceutical formulation (Supplier) & $\begin{array}{c}\text { Expected } \\
\text { tamoxifen } \\
\text { quantity/ } \\
\text { mg }\end{array}$ & $\begin{array}{l}\text { Label } \\
\text { claim, \% }\end{array}$ \\
\hline $\begin{array}{l}\text { NOLVADEX } 10 \mathrm{mg} \text { (Astrazeneca, } \\
\text { Macclesfield, UK) }\end{array}$ & 10 & 99.2 \\
\hline NOLVADEX $20 \mathrm{mg}$ (Astrazeneca) & 20 & 100.4 \\
\hline $\begin{array}{l}\text { TAMOXIFENO CINFA EFG Comp. } 10 \mathrm{mg} \\
\text { (Cinfa, Plamplona, Spain) }\end{array}$ & 10 & 98.7 \\
\hline $\begin{array}{l}\text { TAMOXIFENO CINFA EFG Comp. } 20 \mathrm{mg} \\
\text { (Cinfa) }\end{array}$ & 20 & 99.0 \\
\hline $\begin{array}{l}\text { TAMOXIFENO EDIGEN EFG Comp. } \\
10 \text { mg (Edigen, Madrid, Spain) }\end{array}$ & 10 & 99.8 \\
\hline $\begin{array}{l}\text { TAMOXIFENO EDIGEN EFG Comp. } \\
20 \text { mg (Edigen) }\end{array}$ & 20 & 101.0 \\
\hline $\begin{array}{l}\text { TAMOXIFENO RATIOPHARM EFG } \\
\text { Comp. } 10 \mathrm{mg} \text { (Ratiopharm, Madrid, Spain) }\end{array}$ & 10 & 100.4 \\
\hline $\begin{array}{l}\text { TAMOXIFENO SANDOZ Comp. } \\
10 \text { mg(Sandoz Farmaceutica, Aravaca, } \\
\text { Spain) }\end{array}$ & 10 & 98.4 \\
\hline $\begin{array}{l}\text { TAMOXIFENO SANDOZ Comp. } 20 \text { mg } \\
\text { (Sandoz Farmaceutica) }\end{array}$ & 20 & 98.9 \\
\hline $\begin{array}{l}\text { TAMOXIFENO TORA Comp. } 10 \mathrm{mg} \text { (Tora } \\
\text { Laboratories, Madrid, Spain) }\end{array}$ & 10 & 99.7 \\
\hline $\begin{array}{l}\text { TAMOXIFENO TORA Comp. } 20 \mathrm{mg} \text { (Tora } \\
\text { Laboratories) }\end{array}$ & 20 & 100.2 \\
\hline $\begin{array}{l}\text { TAMOXIFENO UR EFG Comp. } 10 \text { mg } \\
\text { (Uso Racional S.L., Madrid, Spain) }\end{array}$ & 10 & 98.7 \\
\hline $\begin{array}{l}\text { TAMOXIFENO UR EFG Comp. } 20 \mathrm{mg} \\
\text { (Uso Racional S.L.) }\end{array}$ & 20 & 99.8 \\
\hline $\begin{array}{l}\text { YACESAL Comp. } 10 \mathrm{mg} \text { (Laboratorios } \\
\text { Smaller S.A., Madrid, Spain) }\end{array}$ & 10 & 100.4 \\
\hline $\begin{array}{l}\text { YACESAL Comp. } 20 \mathrm{mg} \text { (Laboratorios } \\
\text { Smaller S.A.) }\end{array}$ & 20 & 99.7 \\
\hline
\end{tabular}

significantly affected by small variations of the chromatographic conditions.

\section{Analysis of tamoxifen citrate formulations}

The obtained results in validation indicate that the method is reliable and sufficiently sensitive. The waste produced by the analyses contains mainly biodegradable and non-pollutant reagents (water, SDS, phosphate and sodium chloride) and only a small amount of toxic solvent (7\% of pentanol). Moreover, the entire analysis can be performed in only $30 \mathrm{~min}$ : estimating $\approx 5 \mathrm{~min}$ for sample preparation, $20 \mathrm{~min}$ for TAMO photoactivation and $5 \mathrm{~min}$ for the chromatographic run. Besides, it used relatively inexpensive instrumentation and reagents. Therefore, the analytical methodology is useful for the routine analysis of tamoxifen in formulations.

The content of several TAMO citrate formulations purchased

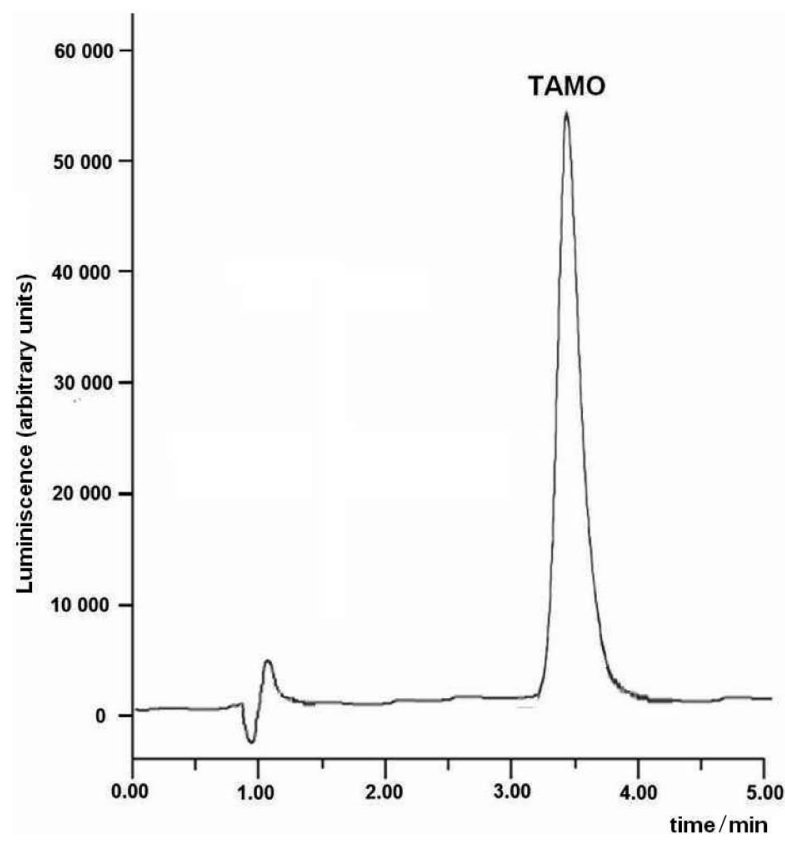

Fig. 2 Chromatogram obtained by the analysis of a NOLVADEX $10 \mathrm{mg}$ tablet under the optimal conditions.

from a local chemist were analyzed $(n=3)$. Since the maximal accuracy and precision was obtained at $10 \mathrm{mg} / \mathrm{L}$, the formulations were diluted in $0.05 \mathrm{M}$ SDS-pH 3 to reach this concentration. This coincides with the central value of the calibration range, where the statistical error is minimized. ${ }^{45}$ In all of the obtained chromatograms, TAMO was eluted without overlapping with other compounds of the matrix, then proving the specificity of the methodology.

The obtained label claims are given in Table 3. The chromatogram corresponding to the analysis of NOVALDEX 10 mg sample is shown in Fig. 2. The measured amount was in all cases similar to those mentioned on the wrapper.

\section{Advantages of the method}

The main feature of the analytical method is strong simplification of the sample preparation, which is expedited to solubilization, photoactivation, filtration and injection. Therefore, chemical derivatization and liquid/liquid extraction $^{17-19}$ are avoided. The elimination of intermediate steps reduces the probability of any operator error, and thus improving the robustness and reproducibility of the method. Other feature is that the sample is quantitatively transferred to the chromatographic system, whereas in, ${ }^{17-19}$ the analyte is previously separated from the matrix. This increases the recovery and the precision, because the yielding of the reaction and extraction can show a slight variability, which is normally under $100 \%$.

Another feature of the method is a reduction of the volume of organic solvent required. Sample preparation is performed in aqueous solutions and inorganic biodegradable reagents, whereas in previously issued methods the use of a toxic organic solvent is required to solubilize the sample $\mathrm{e}^{15,16}$ and to perform liquid/liquid extraction. ${ }^{17-19}$ Moreover, the present method uses a mobile phase with only $7 \%$ of pentanol, whereas the other methods use up to $30 \%{ }^{15}$ and $95 \%$ of acetonitrile. Therefore, the health danger related to the handling of hazardous and flammable compounds, as well as the environmental impact, are 
minimized.

The application of micellar liquid chromatography also introduces important advantages over spectrophotometric methods as well as hydroorganic-HPLC and LC-MS-MS. The use of a separation technique reduces the probability of interference, and thus improves the specificity, if compared to direct spectrophotometry. ${ }^{17-19}$ Moreover, the use of a photoactivation reaction and MLC-FLD analysis allows one to reach a lower LOD than that by derivatization-spectrophotometric analysis $^{19}\left(70 \mathrm{ng} / \mathrm{mL}\right.$ and $2.75 \mu \mathrm{g} / \mathrm{mL}$, respectively). In, ${ }^{16}$ the elution is performed in 9.9 min using a gradient, whereas in the present work the tamoxifen is eluted in $3.5 \mathrm{~min}$ under the isocratic mode.

The here-detailed method allows one to perform the analysis at a lower price, because of shortens of both experimental procedures, compared to ${ }^{17-19}$ and the chromatographic run, ${ }^{15,16}$ the use of fewer amounts of reagents than $i^{15-19}$ and the utilization of basic chromatographic instrumentation, instead of expensive LC-MS-MS. ${ }^{16}$ Moreover, the use of isocratic mode instead of a gradient, ${ }^{15,16}$ facilitates the successive analysis of a large number of samples. For these reasons, the proposed method is available to laboratories with less economic power, and is useful for routine analysis.

\section{Conclusions}

Micellar liquid chromatography is an appropriate technique to determine the amount of active principle (tamoxifen) in the TAMO citrate formulations. The main advantage of the method is simplification of the sample preparation. Due to solubilization of the excipients and the analyte in micellar media, tedious and time-consuming extraction and clean-up steps are not required. TAMO was eluted without interference from the matrix compounds. The concentration of tamoxifen in the formulations is measured with high reliability, due to the adequate values of accuracy, precision and robustness. The analyses can be performed in less than $30 \mathrm{~min}$ at low cost. Moreover, the method is environmentally friendly, since it uses biodegradable inorganic salts and only a small amount of toxic organic solvent.

\section{Acknowledgements}

This work was supported by the project P1.1B2012-36, funded by the Universitat Jaume I. The authors declare that they have no financial/commercial conflicts of interest.

\section{References}

1. A. Jemal, R. Siegel, J. Xu, and E. Ward, Ca-Cancer J. Clin., 2010, 60, 277.

2. C. K. Osborne, N. Engl. J. Med., 1998, 339, 1609.

3. V. C. Jordan and A. M. H. Brodie, Steroids, 2007, 72, 7.

4. Early Breast Cancer Trialists' Collaborative Group, Lancet, 2005, 365, 1687.

5. J. Cuzick, J. F. Forbes, I. Sestak, S. Cawthorn, H. Hamed, K. Holli, and A. Howell, J. Natl. Cancer Inst., 2007, 99, 272.

6. H. Abdulhaq and C. Geyer, Am. J. Clin. Oncol., 2008, 31, 595.

7. V. C. Jordan, Steroids, 2007, 72, 829.

8. R. Clarke, F. Leonessa, J. N. Welch, and T. C. Skaar, Pharmacol. Rev., 2001, 53, 25.
9. R. Simon, J. Latreille, C. Matte, P. Desjardins, and E. Bergeron, Can. J. Surg., 2014, 57, 26.

10. A. C. Moffat, M. D. Osselton, W. Brian, and J. Watts, "Clarke's Analysis of Drugs and Poisons", 2004, Pharmaceutical Press, London.

11. C. M. Buchanan, N. L. Buchanan, K. J. Edgar, J. L. Lambert, J. D. Posey-Dowty, M. G. Ramsey, and M. F. Wempe, J. Pharm. Sci., 2006, 95, 2246.

12. D. P. De Santana, R. M. Carvalho Braga, R. Strattmman, M. Muñiz-Albuquerque, D. C. Galindo Bedor, and L. Bastos Leal, Quím. Nova, 2008, 31, 47.

13. A. Bright, T. S. Renuga Devi, and S. Gunasekaran, Int. J. ChemTech Res., 2010, 2, 865.

14. L. Renner, F. A. Nkansah, and A. N. O. Dodoo, Ann. Oncol., 2013, 24, v29.

15. V. Coopman and J. Cordonnier, Ann. Toxicol. Anal., 2012, $24,73$.

16. M. Thevis, Y. Schrader, A. Thomas, G. Sigmund, H. Geyer, and W. Schänzer, J. Anal. Toxicol., 2008, 32, 232.

17. C. S. Sastry, J. S. Rao, and K. R. Lao, Talanta, 1995, 42, 1479.

18. C. S. P. Sastry and J. S. V. M. Lingeswara Rao, J. Pharm. Sci., 1995, 57, 133.

19. A. Fathima, S. Rao, and G. Venkateshwarlu, Int. J. ChemTech Res., 2012, 4, 79.

20. J. Rodríguez Flores, J. J. Berzas Nevado, G. Castaneda Penalvo, and M. I. Rodríguez Cáceres, Chromatographia, 2002, 56, 283.

21. J. J. Berzas, J. Rodríguez, A. M. Contento, and M. P. Cabello, J. Sep. Sci., 2003, 26, 908.

22. J. Peris-Vicente, R. Garrido-Medina, E. Simó-Alfonso, J. V. Gimeno-Adelantado, and M. T. Doménech-Carbó, Rapid Commun. Mass Spectrom., 2007, 21, 851.

23. Y. B. Zhu, Q. Zhang, J. J. Zou, C. X. Yu, and D. W. Xiao, J. Pharm. Biomed. Anal., 2008, 46, 349.

24. K. L. Lee, B. A. Ward, Z. Desta, D. A. Flockhart, and D. R. Jones, J. Chromatogr. B, 2003, 791, 245.

25. Y. B. Zhu, Q. Zhang, C. X. Yu, J. J. Zou, T. Lu, and D. W. Xiao, Chin. Pharm. J., 2009, 44, 1658.

26. M. Sharma, D. E. Shubert, M. Sharma, J. Lewis, B. P. McGarrigle, D. P. Bofinger, and J. R. Olson, Chem. Biol. Interact., 2003, 146, 237.

27. Y. Jin, Z. Desta, V. Stearns, B. Ward, H. Ho, K. H. Lee, T. Skaar, A. M. Storniolo, L. Li, A. Araba, R. Blanchard, A. Nguyen, L. Ullmer, J. Hayden, S. Lemler, R. M. Weinshilboum, J. M. Rae, D. F. Hayes, and D. A. Flockhart, J. Natl. Cancer Inst., 2005, 97, 30.

28. H. Joshua, Am. Lab., 1998, 30, 104HH.

29. J. Esteve-Romero, E. Ochoa-Aranda, D. Bose, M. RamblaAlegre, J. Peris-Vicente, and A. Martinavarro-Domínguez, Anal. Bioanal. Chem., 2010, 397, 1557.

30. E. Ochoa Aranda, J. Esteve-Romero, M. Rambla-Alegre, J. Peris-Vicente, and D. Bose, Talanta, 2011, 84, 314.

31. M. Rambla-Alegre, S. Marco-Peiró, J. Peris-Vicente, B. Beltrán-Martinavarro, M. A. Collado-Sánchez, S. CardaBroch, and J. Esteve-Romero, Food Chem., 2011, 129, 614.

32. M. Rambla-Alegre, J. Peris-Vicente, J. Esteve-Romero, and S. Carda-Broch, Food Chem., 2010, 123, 1294.

33. I. Casas-Breva, J. Peris-Vicente, M. Rambla-Alegre, S. Carda-Broch, and J. Esteve-Romero, Analyst, 2012, 137, 4327.

34. B. Beltrán-Martinavarro, J. Peris-Vicente, M. RamblaAlegre, S. Marco-Peiró, J. Esteve-Romero, and S. CardaBroch, J. AOAC Int., 2013, 96, 870.

35. M. L. Chin-Chen, S. Carda-Broch, J. Peris-Vicente, M. 
Rambla-Alegre, J. Esteve-Romero, and S. Marco-Peiró, J. Food Compos. Anal., 2013, 29, 32.

36. S. D. Mishra, D. Bose, S. K. Shukla, A. Durgabanshi, and J, Esteve-Romero, Anal. Methods, 2013, 5, 1747.

37. M. Rambla-Alegre, R. Martí-Centelles, J. Esteve-Romero, and S. Carda-Broch, J. Chromatogr. A, 2011, 1218, 4972.

38. S. K. Mourya, S. Dubey, A. Durgabanshi, S. K. Shukla, J. Esteve-Romero, and D. Bose, J. AOAC Int., 2011, 94, 1082.

39. S. Carda-Broch, M. T. Gil-Agustí, M. Rambla-Alegre, L. Monferrer-Pons, and J. Esteve-Romero, J. Chromatogr. A, 2007, 1156, 254.

40. M. Gil-Agustí, S. Carda-Broch, M. E. Capella-Peiró, and J. Esteve-Romero, J. Pharm. Biomed. Anal., 2006, 41, 1235.

41. M. J. Ruiz Ángel, M. T. Gil Agustí, J. Esteve Romero, and S. Carda Broch, LCGC North Am., 2005, 23, 182.
42. D. Bose, A. Durgbanshi, M. E. Capella-Peiró, M. GilAgustí, S. Carda-Broch, and J. Esteve-Romero, Indian J. Chem., Sect. B: Org. Chem. Incl. Med. Chem., 2004, 43, 1973.

43. ICH Harmonized Tripartite Guideline, Validation of Analytical Procedures: Text and Methodologies Q2(R1), Compilation prepared by ICH, Geneva, Switzerland, 2005. Available at: http://www.ich.org/fileadmin/Public_Web_ Site/ICH_Products/Guidelines/Quality/Q2_R1/Step4/Q2_ R1_Guideline.pdf (Last accessed: 15/05/2014).

44. M. Rambla-Alegre, J, Peris-Vicente, S. Marco-Peiró, B. Beltrán-Martinavarro, and J. Esteve-Romero, Talanta, 2010, 81, 894.

45. G. Ramis-Ramos and M. C. García Álvarez-Coque, "Quimiometría", 2001, Síntesis, Madrid, Spain. 